\title{
복합여재 여과시스템을 통한 비점오염물질의 제거효율 평가 Evaluation of the Efficiency of a Combination Media Filter in the Removal of Nonpoint Source Pollution
}

\author{
강경환* · 김중현** · 전현진*** · 변임규**** \\ Kang, Kyeong Hwan*, Kim, Junghyeon**, Jeon, Hyeonjin***, and Byun, Imgyu****
}

\begin{abstract}
Stormwater runoff is a major source of nonpoint source pollution, contributing $22-40 \%$ of the total pollution load in 4 major rivers, which has a significant impact on aquatic ecosystems. The criteria for installation of nonpoint pollution abatement facilities in Korea focuses on the removal of suspended solids. Since the load of dissolved phosphorus and heavy metals in stormwater runoff is increasing, it is necessary to develop a method to reduce dissolved materials as well. In this study, the efficiency of using clay granule, zeolite, blast furnace, and basic oxygen furnace slag (from lab- and pilot-scale experiments) to remove SS, phosphorus, and heavy metals from surface waters was evaluated. Among the four types of filter media, the removal performance of clay granule for SS and basic oxygen furnace slag for phosphorus and heavy metals was excellent. As a result, the clay granule and basic oxygen furnace slag were selected as the filter media. In the pilot column test, $89.5 \%$ of SS, $77.6 \%$ of phosphorus, $87.3 \%$ of $\mathrm{Zn}$, and $67.5 \%$ of $\mathrm{Cu}$ was removed, indicating stable removal efficiency, with a head loss of $3.8 \mathrm{~cm}$. It satisfied the nonpoint pollution abatement facility installation criteria of functioning at a linear velocity $20 \mathrm{~m} / \mathrm{h}$. The clay granule and basic oxygen slag filter would be a useful addition to a nonpoint pollution abatement facility.
\end{abstract}

Key words : Stormwater Runoff, Nonpoint Source, Filter Media, SS Removal, Dissolved Phosphorus and Heavy Metal Removal

\section{요 지}

비점오염원은 지표면의 각종 오염물질들이 강우유출수 형태로 유출되어 수생태계에 큰 영향을 미치고 있으며 4대강으로 유입되는 오염원 부하의 $22-40 \%$ 를 차지할 만큼 심각한 오염원으로 평가되고 있다. 우리나라의 비점오염저감시설 설치 기준은 부유성 고형물의 제거에만 초점이 맞추어져 있다. 그러나 강우유출수 내 용존성 인과 중금속의 부하가 점차 증가하고 있어 용존성 물질의 제거할 수 있는 방법의 개발이 필요하다. 따라서 본 연구에서는 소성점토, 제올라이트, 고로 및 제강슬래그를 이용하여 실험실 규모 및 pilot column을 통해 SS, 인 및 중금속의 제거 효율을 평가하였다. 실험실 규모의 연구에서 4가지 여재 중 소성점토는 SS 제거 효율이 가장 높았고, 제강슬래그는 높은 인과 중금속 제거 효율을 보였다. 이에 따라 소성점토와 제강슬래그가 최적 여재로 선정되었다. Pilot column 실험에서 선속도 조건 $20 \mathrm{~m} / \mathrm{h}$ 에서의 SS, 인과 아연 및 구리의 제거 효율은 각각 $89.5,77.6,87.3$ 및 $67.5 \%$ 로 안정적인 효율을 달성하였고, 손실수두는 $3.8 \mathrm{~cm}$ 로 선속도 $20 \mathrm{~m} / \mathrm{h}$ 조건에서도 비점오염저감 시설 설치 기준에 만족하였다. 소성점토와 제강슬래그는 비점오염저감시설에도 충분히 적용될 수 있을 것으로 보인다.

핵심용어 : 강우유출수, 비점오염원, 여재, SS 제거, 용존성 인·중금속 제거

*정회원, 부산대학교 환경·에너지연구소 연수연구원(E-mail: kangkh21@pusan.ac.kr)

Member, Post-doctoral, Institute for Environmental Technology and Industry, Pusan National University

***부산대학교 사회환경시스템공학과 석사과정

Master Course, Department of Civil and Environmental Engineering, Pusan National University

****부산대학교 사회환경시스템공학과 석사과정

Master Course, Department of Civil and Environmental Engineering, Pusan National University

****교신저자, 정회원, 부산대학교 환경 - 에너지연구소 부교수(Tel: +82-51-510-7381, Fax: +82-51-581-5035, E-mail: big815@pusan.ac.kr)

Corresponding Author, Member, Associate professor, Institute for Environmental Technology and Industry, Pusan National University 


\section{1. 서 론}

수질오염원은 도시나 공장에서와 같이 지속적으로 발생 하는 점오염원(point source)과 주로 강우 시 도시의 도로, 주거지역 및 농촌의 논, 밭, 임야에서 흘러나오는 오염된 강우유출수 형태로 발생하는 비점오염원(nonpoint source) 로 구분할 수 있다. 비점오염원에는 토사, 영양물질, 유기물 질, 박테리아 및 중금속 등이 포함되어 있다(Okochi and McMartin, 2012). 이러한 비점오염원이 강우 시 지표에 축적 되어있던 각종 오염물질들이 유출되어 단시간 내에 강과 하천에 유입되어 수생태계에 큰 영향을 미치고 있다(Kwon et al., 2017). 지금까지 우리나라에서는 점오염원 위주의 수질관리가 시행되고 있으나, 4 대강 수계에 미치는 비점오 염원의 부하는 4대강으로 유입되는 전체 오염원의 약 $22-40 \%$ 를 차지한다(Lee and Lee, 2009). 이러한 비점오염원 은 측정 및 정량이 어렵고 흐름을 예측하기 쉽지 않아 관리가 쉽지 않다는 문제점이 있다. 따라서 비점오염저감시설의 설치를 통하여 강우유출수 내 오염원을 처리하거나, 저영향 개발(low impact development, LID) 등을 통해 강우 시 비점 오염의 유출을 줄이는 등의 연구가 진행되고 있다.

비점오염저감시설은 침투형과 인공습지와 같은 자연형 시설과 와류형과 여과형 시설과 같은 장치형 시설로 구분된다. 자연형 시설은 우리나라와 같이 면적이 좁은 경우 이용하는 데 제한적이나, 장치형 시설은 이와 반대로 여재(filter media) 를 이용한 시설로 좁은 공간에서도 설치할 수 있으며 빠른 속도로 강우유출수를 처리할 수 있다. 비점오염원 중 강우유 출수의 수질 상태를 파악할 수 있는 주 오염물질은 부유성 고형물(suspended solid, SS)로 유기물, 무기물 등을 함께 수반하고 있으며, 강우 시 초기 세척 현상을 통해 고농도의 비점오염원을 유출한다. 따라서 $\mathrm{SS}$ 의 제거율은 다른 오염물 질들의 제거율 지표로도 이용될 수 있다고 여겨지고 있다 (Hwang et al., 2017). 이러한 이유로 우리나라의 '비점오염저 감시설 설치 및 관리· 운영 매뉴얼'(ME, 2016)에 제시된 오염원의 제거는 $\mathrm{SS}$ 의 제거에만 $80 \%$ 이상으로 명시되어 있으며, 다른 용존성 물질에 대한 기준은 제시되어 있지 않다.

그러나, SS 이외에도 강우유출수 내 용존성 인(ortho phosphate)과 중금속은 적은 농도로 유입되더라도 그 부피와 유량이 많을 경우 부하가 크기 때문에 수계에 큰 영향을 미친다. 실제 공업지대의 강우유출수에는 SS 외에도 인과 중금속이 심각한 문제가 될 수 있고 강우유출수 내 인과 중금속의 부하가 점차 증가하고 있다(Choi and Shin, 2002). 또한 용존성 중금속과 이온물질은 강우유출수에 의한 초기 세척효과(first flush effect)가 일어나지 않아 강우유출수와 함께 지속적으로 유입된다(Soller et al., 2005). 이러한 용존성 물질은 이동성이 높아 쉽게 수계 내에서 퍼질 수 있으며, 잠재적 인 생체독성물질이 될 수 있다(Joshi and Balasubramanian,
2010). 따라서, 향후 비점오염저감시설의 설치 기준이 강화 될 것으로 예상되고 있으며, 이에 따라 비점오염저감시설에 적용하여 강우유출수 내 인과 중금속의 제거가 가능한 여재 의 개발이 요구되고 있다. 현재 황토(clay loess), 셰일(shale), 플라이애쉬(fly ash), 제올라이트(zeolite), 철강슬래그(steel slag) 등과 같은 천연물질 혹은 산업 부산물을 이용하여 폐수 내 인과 중금속을 침전과 흡착을 통해 제거하는 연구가 진행되어 왔다(Bowden et al., 2009; Shin et al., 2011; Kim et al., 2014).

여재의 특성에 따라 여과형 비점오염저감시설에 의한 강우유출수의 처리 효율, 여과속도 장치의 규모 등이 결정된 다(Kim et al., 2009). 또한 여과형 비점오염저감시설에서 여재의 교체 비용은 여과형 시설의 운영비용 중 대부분을 차지한다. 따라서 교체주기가 길고 가격이 저렴한 여재를 사용할 필요가 있다. 또한, 이러한 여재들을 비점오염저감시 설에 적용하기 위해서는 '비점오염저감시설 설치 및 관리 운영 매뉴얼'에 제시되어 있는 유입선속도 $(20 \mathrm{~m} / \mathrm{h}$ 이하 $)$, 여재의 막힘현상에 따른 시설의 손실수두 $(10 \mathrm{~cm}$ 이하 $)$ 등을 고려하여야 한다. 여과형 비점오염저감시설에서 하향류 방 식의 시설은 $\mathrm{SS}$ 의 처리효율은 높지만 여재의 막힘 현상이 일어난다는 문제점이 있으며, 상향류 방식의 시설 여재의 막힘현상은 적으나 처리효율이 하향류 방식에 비해 낮다는 단점이 있다(Kim et al., 2010; Lee et al., 2015). 따라서 여재 특성에 따라 강우유출수의 흐름을 제어할 수 있는 최적화된 여과형 비점오염저감시설의 구성 및 설계가 필요하다.

따라서 본 연구에서는 비점오염물질 제거를 위하여 소성 점토, 제올라이트 및 철강슬래그(고로슬래그, 제강슬래그) 를 이용하여 SS, 인 및 중금속의 제거 효율을 평가하였다. 또한 실험실 규모에서의 SS제거를 위한 여과 실험과 인, 중금속 제거를 위한 회분식 실험 및 column형 pilot 규모의 연속식 실험에서 복합여재에 의한 각 오염물질들의 동시 처리를 통한 제거 효율 및 손실수두를 분석하여 비점오염저 감시설 적용 가능성을 검토 및 평가하였다.

\section{2. 재료 및 방법}

\section{1 실험재료}

본 연구에서 이용된 대상 여재는 기존에 비점오염저감시 설에서 $\mathrm{SS}$ 제거용으로 널리 이용되는 여재인 소성점토(clay granule, $\mathrm{CG}$ )와, 인과 중금속 흡착제로 쓰이는 천연제올라이 트(natural zeolite, ZE), 고로슬래그(blast furnace slag, BFS) 와 제강슬래그(basic oxygen furnace slag, BOFS)를 이용하였 으며 Table 1에 그 물리·화학적 특성을 나타내었다.

여재의 SS 제거 효율을 평가하기 위하여 '비점오염저감시 설의 설치 및 관리·운영 매뉴얼'에 따라 규사를 입경 63 $\mu \mathrm{m}$ 이하 $(80 \%)$ 와 63-200 $\mu \mathrm{m}(20 \%)$ 를 혼합하였다. 또한 인과 중금속은 인산칼륨 $\left(\mathrm{KH}_{2} \mathrm{PO}_{4}\right)$ 과 아연 표준용액을 이용하여 
Table 1. Physico-chemical Properties of Filter Media

\begin{tabular}{|c|c|c|c|c|c|}
\hline \multicolumn{2}{|r|}{ Properties } & Clay granule ${ }^{1), 2)}$ & Zeolite $^{2)}$ & Blast furnace slag $^{2)}$ & Basic oxygen furnace slag ${ }^{1), 2)}$ \\
\hline \multirow{3}{*}{ Physical } & Porosity (\%) & 50.0 & 38.4 & 32.0 & 40.1 \\
\hline & Particle size $(\mathrm{mm})$ & $2.5-4.0$ & $3.0-5.0$ & $2.5-13.0$ & $2.5-13.0$ \\
\hline & Specific gravity & 1.2 & 2.2 & 2.9 & 3.1 \\
\hline \multirow{5}{*}{ Chemical } & $\mathrm{SiO}_{2}$ & 63.0 & 67.4 & 32.8 & 14.8 \\
\hline & $\mathrm{Al}_{2} \mathrm{O}_{3}$ & 17.0 & 13.7 & 14.8 & 1.5 \\
\hline & $\mathrm{Fe}_{2} \mathrm{O}_{3}$ & 7.0 & 1.89 & 0.4 & 17.4 \\
\hline & $\mathrm{MgO}$ & 5.0 & 0.99 & 5.2 & 6.3 \\
\hline & $\mathrm{CaO}$ & 2.0 & 3.27 & 41.2 & 46.1 \\
\hline
\end{tabular}

※ Source: ${ }^{1)}$ Korea testing \& Research Institute, ${ }^{2)}$ Report from supplier

$\mathrm{PO}_{4} \mathrm{P}, \mathrm{Zn}$ 혼합 용액을 제조하였다. Pilot test를 위한 인공강 우유출수는 Choi and Shin (2002)에 제시된 도시, 상업지역 및 공업지역의 강우유출수 농도를 바탕으로 $\mathrm{SS}$ 는 $250 \mathrm{mg} / \mathrm{L}$, 인과 중금속은 인산칼륨과 아연, 구리 표준용액을 이용하여 $0.5,0.7$ 및 $0.2 \mathrm{mg} / \mathrm{L}$ 로 제조하였다.

\section{2 실험 방법}

\subsubsection{SS 처리를 위한 column 실험}

$\mathrm{SS}$ 제거를 위한 여재선정을 위해 내경 $10 \mathrm{~cm}$, 높이 60 $\mathrm{cm}$ 인 아크릴 column을 이용하여 각 column에 여재를 충전하 였고, 양 끝에 여재의 유실을 방지하기 위하여 메쉬 소재의 그물망으로 고정하였다. 유입수는 $1.8 \mathrm{~L} / \mathrm{min}$ 으로 유입하였다

(Table 2).

\subsection{2 용존성 물질 처리효율 평가를 위한 회분실험} 회분식 실험은 각 여재의 인, 중금속 제거효율을 평가하기
위하여 실행되었다. 인, 아연 혼합용액 $300 \mathrm{~mL}$ 에 각 여재 $100 \mathrm{~g}$ 을 투입하여 24시간 동안의 제거 효율을 평가하였다. 또한 시간 당 비흡착량을 평가하였으며, 사용 된 여재 중 인, 중금속 제거효율이 가장 높은 여재를 대상으로 여재 투입량을 다르게 하여 흡착등온식을 유도하였다(Table 3).

\subsection{3 복합 여재를 이용한 pilot column 실험}

$\mathrm{SS}$ 제거 실험과 인과 중금속 제거를 위한 회분식 실험에서 도출된 여재를 이용하여 pilot column 반응기에 적용하여 $\mathrm{SS}$, 인, 아연 및 구리의 제거 효율을 평가하였다. 본 연구에서 이용된 pilot column의 직경은 $20 \mathrm{~cm}$ 이고, 단면적은 3.14 $\times 10^{-2} \mathrm{~m}^{2}$ 이며, 여과 길이를 $120 \mathrm{~cm}$ 로 설정하였다. '비점오염 저감시설의 설치 및 관리·운영 매뉴얼에 제시된 강우유출 수의 유입은 선속도 $20 \mathrm{~m} / \mathrm{h}$ 이하로 규정되어 있기 때문에 이에 따라 유입 유량은 선속도 $12.5,15$ 및 $20 \mathrm{~m} / \mathrm{h}$ 조건인 각각 6.6, 7.9 및 $10.5 \mathrm{~L} / \mathrm{min}$ 으로 설정하여 유입하였다. 여과 지속시간은 '비점오염저감시설의 설치 및 관리· 운영 매뉴

Table 2. Experiment Condition for SS Removal in Column Experiment

\begin{tabular}{c|c|c|c}
\hline Experiment & Initial concentration $(\mathrm{mg} / \mathrm{L})$ & Description & Filtration running time \\
\hline SS removal & $250^{1)}$ & $\begin{array}{c}\text { Acryl column } \\
\text { (diameter: } 10 \mathrm{~cm} ; \text { height: } 60 \mathrm{~cm})\end{array}$ & $30 \mathrm{mins}$ \\
& & Flow rate: $1.8 \mathrm{~L} / \mathrm{min}$ & \\
\hline
\end{tabular}

${ }^{1)}$ Silica sand

Table 3. Experiment Condition for $\mathrm{P}$ and Heavy Metal Removal in Batch Experiment

\begin{tabular}{|c|c|c|c|}
\hline Experiment & Initial concentration $(\mathrm{mg} / \mathrm{L})$ & Description & Agitation time \\
\hline $\mathrm{P}$ removal & $250^{1)}$ & \multirow{3}{*}{$\begin{array}{c}\text { Batch } \\
(\text { Jar-tester at } 120 \mathrm{rpm})\end{array}$} & $24 \mathrm{hrs}$ \\
\hline $\mathrm{Zn}$ removal & $250^{2)}$ & & $24 \mathrm{hrs}$ \\
\hline Adsorption capacity & $250^{3)}$ & & $\begin{array}{l}\text { Until adsorption } \\
\text { equilibrium is reached }\end{array}$ \\
\hline
\end{tabular}

${ }^{1)}$ Potassium phosphate monobasic $\left(\mathrm{KH}_{2} \mathrm{PO}_{4}\right)$

${ }^{2)} \mathrm{Zn}$ standard solution $(1,000 \mathrm{mg} / \mathrm{L})$

${ }^{3)} \mathrm{P}$ and $\mathrm{Zn}$ mixed solution $(250 \mathrm{mg} / \mathrm{L}$ each) 
Table 4. Experimental Conditions for Removal SS, P and Heavy Metal Simultaneously in Pilot Column System

\begin{tabular}{c|c|c|c}
\hline Experiment & Initial concentration $(\mathrm{mg} / \mathrm{L})$ & Description & Filtration running time \\
\hline $\mathrm{SS}$ removal & $250^{1)}$ & & \\
$\mathrm{P}$ removal & $0.5^{2)}$ & Acryl column & $2 \mathrm{hrs}$ \\
$\mathrm{Zn}$ removal & $0.7^{3)}$ & (diameter: $20 \mathrm{~cm} ;$ height: $120 \mathrm{~cm})$ & \\
$\mathrm{Cu}$ removal & $0.2^{4)}$ & & \\
\hline $\mathrm{Head}$ loss & - & Flow rate: $6.6,7.9$ and $10.5 \mathrm{~L} / \mathrm{min}$ & \\
\hline
\end{tabular}

\footnotetext{
${ }^{1)}$ Silica sand

${ }^{2)}$ Potassium phosphate monobasic $\left(\mathrm{KH}_{2} \mathrm{PO}_{4}\right)$

${ }^{3)} \mathrm{Zn}$ standard solution $(1,000 \mathrm{mg} / \mathrm{L})$

${ }^{4)} \mathrm{Cu}$ standard solution $(1,000 \mathrm{mg} / \mathrm{L})$
}

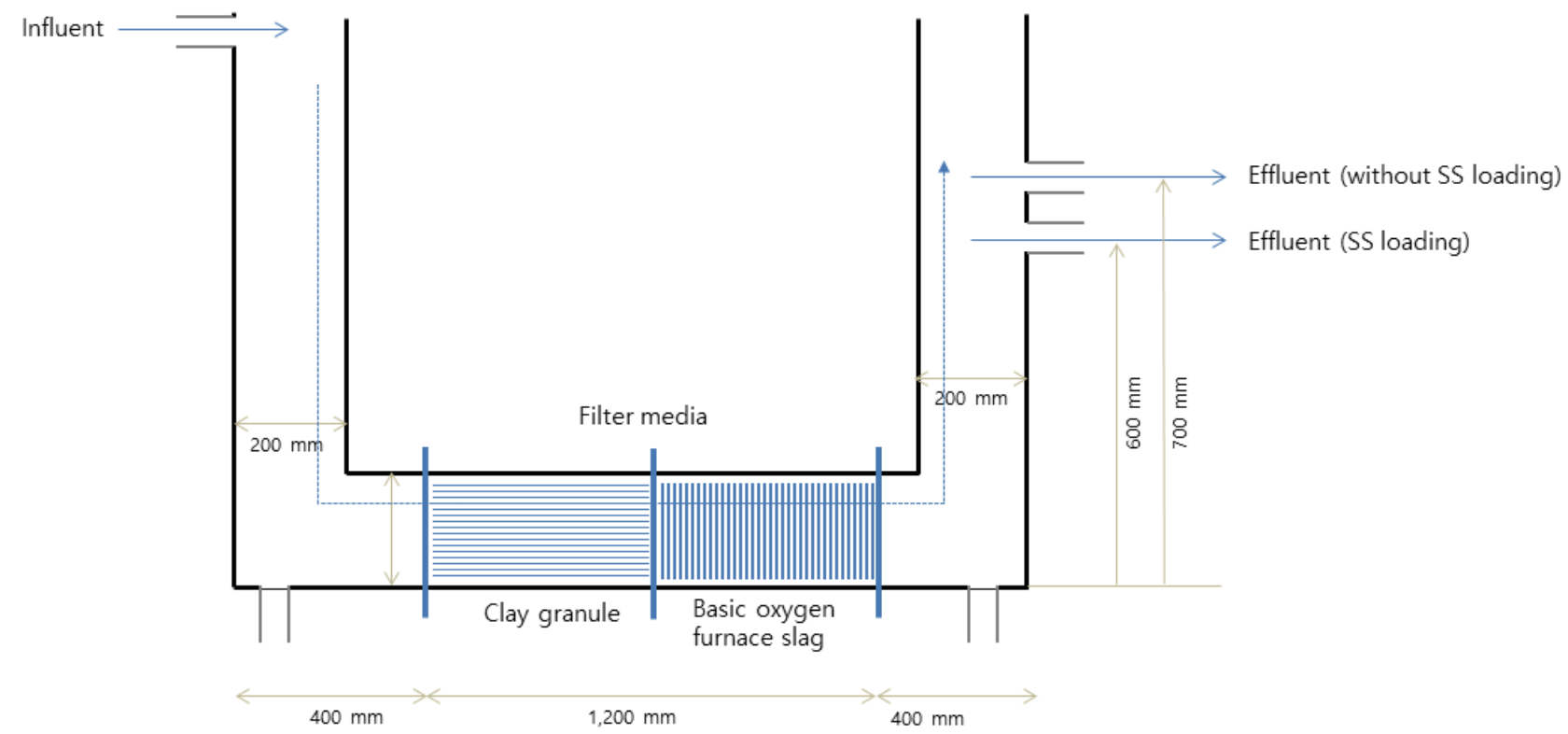

Fig. 1. Schematic of Pilot Column Reactor

얼'에 따라 기준강우강도 $(2.5 \mathrm{~mm})$ 와 누적유출고 $(5 \mathrm{~mm})$ 를 고려하여 2시간동안 진행하였다(Table 4).

또한 pilot column에서의 손실수두를 파악하기 위하여 $\mathrm{U}$ 자 형태로 제작하여 유입 높이는 $100 \mathrm{~cm}$ 로 하였으며, 유출 높이는 $70 \mathrm{~cm}$ 로 설정하였다(Fig. 1). 또한 유입, 유출 및 여재부는 플랜지 형태로 연결하여 여재 교체 등에 의한 탈부 착이 가능하도록 하였다.

\section{3 분석 방법}

$\mathrm{SS}$ 분석은 수질오염공정시험기준에 따라 분석하였고 (ME, 2014), 인 $\left(\mathrm{PO}_{4}-\mathrm{P}\right)$ 과 중금속의 농도 분석은 표준 분석 방법(APHA-AWWA-WEF, 2005)을 이용하였다. 수용액을 $0.45 \mu \mathrm{m}$ cellulose-acetate 필터로 여과 한 후, 자외선 가시 분광 광도계(OPTIZEN 2120UV, MECASYS, South Korea) 를 이용한 몰리브덴 블루-아스코르브 산 방법 및 유도 결합 플라즈마 광 방출 분광법(ICP-OES, PerkinElmer, USA)를 사용하여 분석하였다.
또한 모든 실험 및 분석은 3 회 반복 수행하여 평균값을 제시하였다.

\section{3. 결과 및 고찰}

\section{1 실험실 규모 연구를 통한 평가}

\subsection{1 여재 별 SS 제거 특성}

각 여재에 의한 SS 제거 특성을 파악하기 위하여 column 여과 실험을 실시한 결과를 Fig. 2에 나타내었다. 네 가지 여재 중 소성점토의 SS 제거 효율이 $91.3 \%$ 로 가장 높았으며, 이는 '비점오염저감시설 설치 및 관리· 운영 매뉴얼'에서 권고하는 SS 제거 효율 $80 \%$ 이상을 만족하였다. 그러나 제올 라이트의 SS 제거 효율은 $55.0 \%$ 로 '비점오염저감시설 설치 및 관리·운영 매뉴얼'에서 권고하는 제거 효율을 달성하지 못하였으며, 고로슬래그 및 제강슬래그는 제거효율이 16.5 및 $19.2 \%$ 로 거의 제거되지 않고 유출되었다. 여재 입자 크기, 
여재의 공극률 및 SS 입자 크기는 여과 효율을 결정하는 요소이며(Ko et al., 2006; Kim et al., 2009), 본 연구에서 소성점토의 여과 효율이 가장 높앗던 것은 입자 크기가 작고 공극률이 크기 때문으로 판단되다. 제강슬래그의 경우에는 제올라이트에 비해 공극률은 작으나 입자 크기가 상대적으로 크기 때문에 여과효율이 낮았다. 본 연구에서 제조된 SS 유입수에 포함된 입자는 $63 \mu \mathrm{m}$ 이하의 입자가 $80 \%$ 이상이었 으며, 소성점토는 이러한 작은 입자의 여과에도 우수한 효율 을 나타낸 것으로 판단된다. Brown et al. (2009)은 강우유출수 에 포함된 SS의 $85 \%$ 이상은 $75 \mu \mathrm{m}$ 이하의 입자로 구성되어 있다고 하였으며 $75 \mu \mathrm{m}$ 이하 $\mathrm{SS}$ 입자의 제거 효율이 전체 여과 효율을 결정한다고 보았다. 또한 본 연구에서 이용된 고로슬래그와 제강슬래그의 경우 표면이 일정하지 않아 입자 간 간극이 큰 것으로 나타났는데, Lim et al. (2012)의 연구에서 입자간 간극이 입자 크기나 공극률보다 여과 효율을 결정하 는 지배적인 요인이 될 수 있다고 보고하였다.

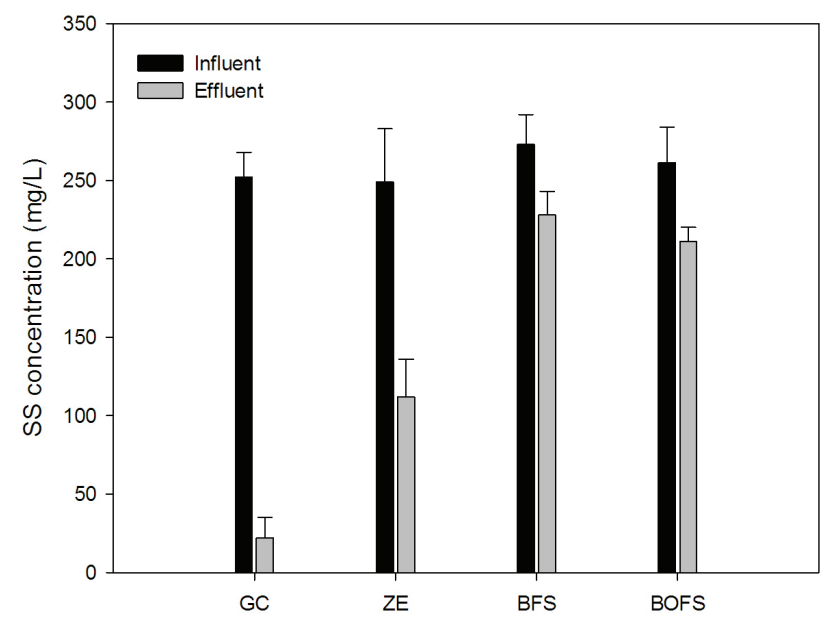

Fig. 2. SS removal Efficiency According to the Filter Media

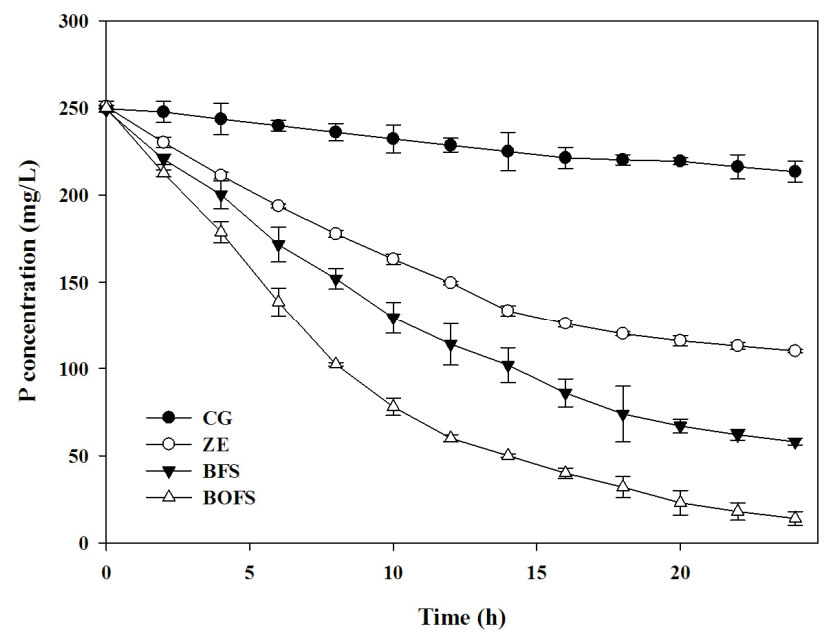

(a)
3.1.2 회분식 실험에서 여재 별 인 및 중금속 제거 특성

각 여재에 의한 인 및 중금속 제거 효율을 분석하기 위하여 $\mathrm{PO}_{4}-\mathrm{P}$ 와 $\mathrm{Zn}$ 의 농도를 각각 $250 \mathrm{mg} / \mathrm{L}$ 로 고정하여 시료를 제조하고 jar-tester를 이용하여 제거 효율을 확인 하였다.

소성 점토, 제올라이트, 고로슬래그 및 제강슬래그 여재 중 인과 중금속 제거 효율이 가장 높은 여재는 제강슬래그로 나타났으며, 소성점토의 경우 인과 중금속을 거의 제거하지 못하였다(Fig. 3). 제올라이트와 슬래그에 함유된 $\mathrm{Ca}, \mathrm{Fe}$ 와 같은 미네랄 성분들은 인을 흡착하여 제거할 수 있으며 (Sakadevan and Bavor, 1998; Chen et al., 2006), 제올라이트 의 $\mathrm{Al}^{3+}$ 와 $\mathrm{Si}^{4+}$ 는 양이온 금속과의 이온교환을 통해 제거할 수 있다(Erdem et al., 2004). 제강슬래그는 수용액 상에서 $\mathrm{CaO}$ 성분이 $\mathrm{Ca}^{2+}$ 와 $\mathrm{OH}^{-}$로 빠르게 해리되고, 인과 중금속 성분이 $\mathrm{Ca}-\mathrm{P}$ 와 $\mathrm{M}-\mathrm{OH}$ 형태로 결합하여 제거된다(Drizo et al., 2006; Xue et al., 2009). Barca et al. (2012)는 인 성분의 함유된 수용액 상에서, 인은 $\mathrm{pH}$ 에 따라 $\mathrm{H}_{3} \mathrm{PO}_{4}, \mathrm{H}_{2} \mathrm{PO}_{4}{ }^{-}$, $\mathrm{HPO}_{4}^{2-}, \mathrm{PO}_{4}^{3-}$ 형태로 존재하는데 이에 따라 소비되는 제강슬 래그에서 해리된 $\mathrm{Ca}^{2+}$ 의 양이 달라지고 생성된 $\mathrm{Ca}-\mathrm{P}$ 화합물 은 침전이나 슬래그 표면에 결정화된다고 하였다. 이 때, 슬래그에서 수용액 상으로 해리된 $\mathrm{OH}^{-}$는 수용액 상의 $\mathrm{pH}$ 를 증가시키는데, 이로 인해 반응 물질 표면은 음전하를 띄는 공간이 증가하여 침전 등에 의해 중금속성분의 제거율이 증가할 수 있다고 하였다(Balkaya and Cesur, 2008; Kim et al., 2011). 이러한 결과와 마찬가지로, 본 연구에서 이용한 제강슬래그는 다른 여재들에 비해 우수한 인과 중금속 제거 효율을 보였는데, 회분식 실험 후 24 시간동안 각 여재의 인과 중금속 제거율은 소성점토는 $14.5,6.9 \%$, 제올라이트는 $56.1,44.7 \%$, 고로슬래그는 $76.7,83.1 \%$, 제강슬래그는 94.4, $99.9 \%$ 로 나타났다(Table 5).

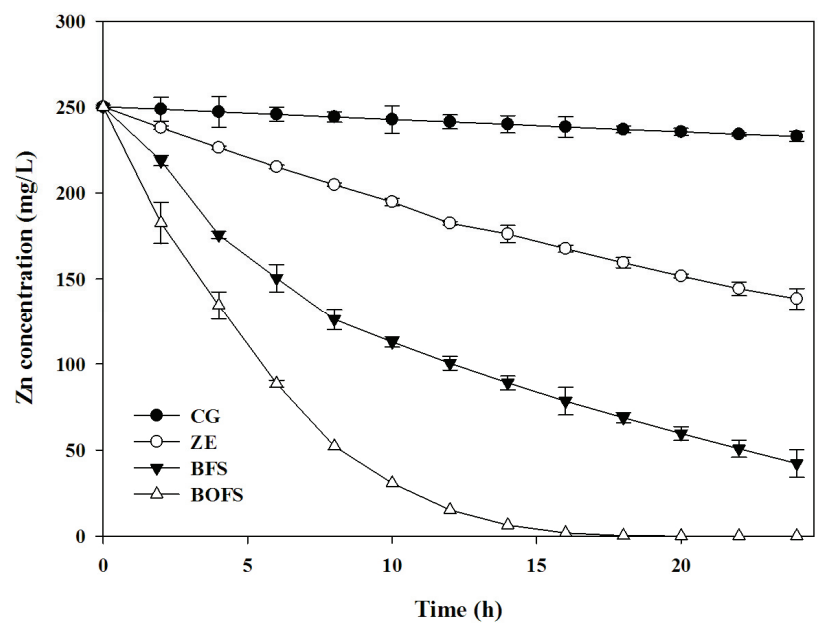

(b)

Fig. 3. Change in the $\mathrm{PO}_{4}-\mathrm{P}$ (a) and $\mathrm{Zn}$ (b) Concentration According to the Time in Batch Experiments 
Table 5. $\mathrm{PO}_{4}-\mathrm{P}$ and $\mathrm{Zn}$ Removal Efficiency According to the Filter Media for $24 \mathrm{~h}$

\begin{tabular}{c|c|c}
\hline \multirow{2}{*}{ Filter media } & \multicolumn{2}{|c}{ Removal (\%) } \\
\cline { 2 - 3 } & $\mathrm{P}$ & $\mathrm{Zn}$ \\
\hline Clay granule & 14.5 & 6.9 \\
Zeolite & 56.1 & 44.7 \\
Blast Furnace Slag & 76.9 & 83.1 \\
\hline Basic Oxygen Furnace Slag & 94.4 & 99.9 \\
\hline
\end{tabular}

인과 아연의 제거는 실험 초기에 빠르게 진행되었는데, 실험 시작 2시간 후의 결과를 바탕으로 인과 아연의 비흡착량 (specific removal capacity)을 산정하였다(Table 6). 제강슬래 그는 다른 여재들에 비해 높은 비흡착량을 나타내고 있으며, 이러한 결과는 여과형 비점오염저감시설에서 강우유출수가 선속도가 $20 \mathrm{~m} / \mathrm{h}$ 로 매우 빠르게 유입될 때 오염물질의 제거 에 있어서 유리하게 작용할 것으로 판단된다. 따라서 비점오 염저감시설에 이용하기 위해서는 단시간 내에 높은 처리 효율을 보이는 여재를 이용 할 필요가 있다. 따라서 본 연구에 서는 SS 제거를 위한 소성점토 여재와 인과 중금속의 처리를 위한 제강슬래그를 이용하였다.

Table 6. Specific $\mathrm{PO}_{4}-\mathrm{P}$ and $\mathrm{Zn}$ Removal Capacity According to the Filter Media for $2 \mathrm{~h}$

\begin{tabular}{c|c|c}
\hline \multirow{2}{*}{ Filter media } & $\begin{array}{c}\text { Specific removal capacity } \\
(\mathrm{mg} / \mathrm{kg} / \mathrm{min})\end{array}$ \\
\cline { 2 - 3 } & $\mathrm{P}$ & $\mathrm{Zn}$ \\
\hline Clay granule & 0.17 & 0.12 \\
Zeolite & 1.72 & 1.02 \\
Blast Furnace Slag & 2.35 & 2.62 \\
\hline Basic Oxygen Furnace Slag & 3.13 & 5.63 \\
\hline
\end{tabular}

\subsection{3 제강슬래그의 인, 중금속 흡착 등온식 평가}

흡착등온식은 흡착 평형이 이루어졌을 때 물질의 흡착 량과 평형농도와의 관계를 나타내는 식이다. 본 연구에서 는 Langmuir식(Eq. 1)과 Freundlch식(Eq. 2)을 적용하여 제강슬래그의 흡착성능을 평가하였다. Langmuir 흡착등온 식은 흡착이 단분자층(monolayer)으로 흡착하는 경우에 나타나는 것으로 알려져 있으며, 이와 반대로 Freundlich 흡착등온식은 흡착열이 표면 덮힘의 정도에 따라 지수적 으로 감소됨을 가정하여 유도된 식이다(Jha et al., 2008;

Gong et al., 2009).

$$
\begin{array}{ll}
\text { Langmuir: } & \mathrm{Q}_{\mathrm{e}}=\mathrm{Q}_{\mathrm{m}} \mathrm{C}_{\mathrm{e}} /\left(1+\mathrm{K}_{\mathrm{L}} \mathrm{C}_{\mathrm{e}}\right) \\
\text { Freundlich: } & \mathrm{Q}_{\mathrm{e}}=\mathrm{K} \cdot \mathrm{C}_{\mathrm{e}}{ }^{1 / \mathrm{n}}
\end{array}
$$

여기에서 Qe $(\mathrm{mg} / \mathrm{g})$ 는 단위 흡착제 질량 당 흡착된 인과
아연의 양, $\mathrm{Ce}(\mathrm{mg} / \mathrm{L})$ 는 인과 아연의 평형 농도를 나타낸 것이다. 또한 $\mathrm{Q}_{\mathrm{m}}(\mathrm{mg} / \mathrm{g})$ 과 $\mathrm{K}_{\mathrm{L}}(\mathrm{L} / \mathrm{mg})$ 은 각각 최대흡착량과 흡착에너지를 나타낸 Langmuir 상수이고, $\mathrm{K}(\mathrm{mg} / \mathrm{g})$ 와 $\mathrm{n}$ 은 흡착능과 흡착 강도를 평가하는 Freundlich 상수이다.

Fig. 4에는 제강슬래그의 인과 중금속 흡착 등온선을 나타 내었고 Table 7에 Langmuir식과 Freundlich 상수와 결정계수 $\left(\mathrm{R}^{2}\right)$ 값을 나타내었다. 결정계수 값에 따라 본 연구에서 제강슬래그에 의한 인의 흡착은 Langmuir 식을, 아연의 제거는 Freundlich 식을 따르는 것으로 나타났다. 일반적으 로 Langmuir 흡착 등온식을 따르는 경우 흡착제의 표면은 제한된 수의 흡착 사이트(adsorption site)를 가지고 있어 모든 흡착 사이트가 채워지면 더 이상 흡착이 될 수 없다. 이와 반대로 Freudlich 흡착 등온식을 따르는 경우에는 흡착 사이트가 각각 다른 흡착 에너지를 가지고 있으며 다분자층 으로 흡착된다(Ayawei et al., 2017).

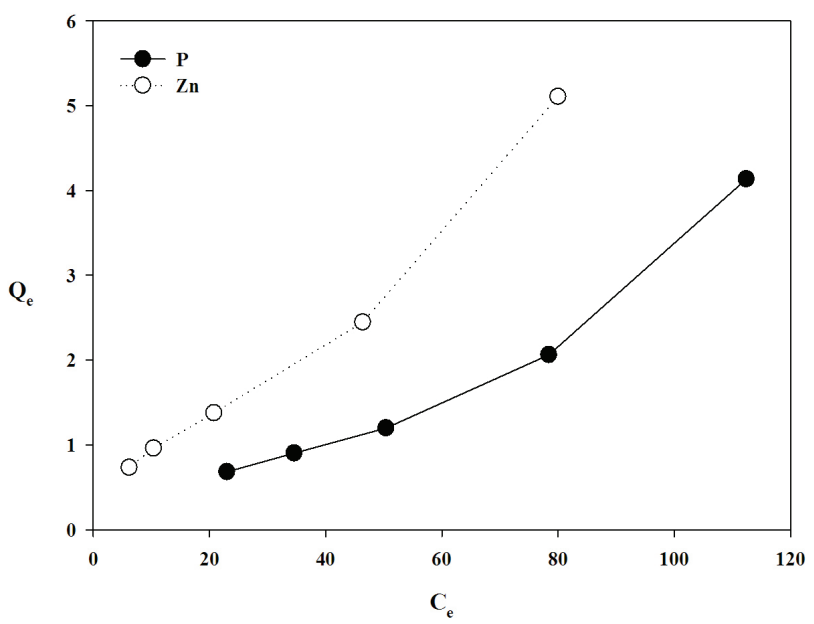

Fig. 4. Adsorption Isotherm for Phosphate and Zinc of Basic Oxygen Furnace Slag

\subsection{Pilot column 반응기에서의 SS, 인, 중금속 제거 특성 및 손실수두 평가}

소성점토 여재와 제강슬래그 여재의 비점오염저감시설 적용 가능성을 평가하기 위하여 pilot column 반응기를 이용 하여 진행하였다. $\mathrm{SS}$ 를 먼저 제거한 후 용존 인과 중금속을 제거하기 위하여 전단에 소성점토를, 후단에 제강슬래그를 배치하였고 선속도는 $12.5,15$ 및 $20 \mathrm{~m} / \mathrm{h}$ 조건에서 수행되었 다. 일반적으로 입경이 작은 여재를 이용할 경우 막힘현상이 발생하여 비점오염저감시설의 기능을 상실하게 된다(Lee et al., 2018). 따라서 여재의 수두손실을 파악하기 위하여 '비점오염저감시설 설치 및 관리·운영 매뉴얼'에 따라 실험 은 SS 부하가 4 6 kg SS/m${ }^{2}$ 의 $150 \%$ 에 도달하는 6 9 kg $\mathrm{SS} / \mathrm{m}^{2}$ 이상 진행하였다.

Pilot column을 이용한 소성점토 여재와 제강슬래그의 2단 여과에서 $\mathrm{SS}$ 의 제거는 선속도가 낮을수록 제거 효율이 
Table 7. Freundlich and Langmuir Isotherm Constant in Basic Oxygen Furnace Slag

\begin{tabular}{c|c|c|c|c|c}
\hline & \multicolumn{2}{|c|}{ Langmuir isotherm constant } & \multicolumn{2}{|c}{ Frendlich isotherm constant } \\
\cline { 2 - 5 } & $\mathrm{P}$ & $\mathrm{Zn}$ & & $\mathrm{P}$ & $\mathrm{Zn}$ \\
\hline $\mathrm{Q}_{\mathrm{m}}(\mathrm{mg} / \mathrm{g})$ & 23.75 & 4.14 & $\mathrm{n}$ & 57.31 & 5.74 \\
$\mathrm{~K}_{\mathrm{L}}(\mathrm{L} / \mathrm{mg})$ & 0.0012 & 0.0322 & $\mathrm{R}^{2}$ & 0.8933 & 1.3734 \\
\hdashline $\mathrm{R}^{2}$ & 0.9566 & 0.9455 & 0.9528 & 0.9627 \\
\hline
\end{tabular}

Table 8. SS Removal According to the Linear Velocity

\begin{tabular}{|c|c|c|c|c|c|}
\hline \multirow{2}{*}{ Linear velocity $(\mathrm{m} / \mathrm{h})$} & \multicolumn{2}{|c|}{ Concentration $(\mathrm{mg} / \mathrm{L})$} & \multirow{2}{*}{$\begin{array}{c}\text { Removal } \\
(\%)\end{array}$} & \multirow{2}{*}{$\begin{array}{c}\text { Loading } \\
\left(\mathrm{kg} \mathrm{SS} / \mathrm{m}^{2}\right)\end{array}$} & \multirow{2}{*}{$\begin{array}{c}\text { Head loss } \\
(\mathrm{cm})\end{array}$} \\
\hline & Influent & Effluent & & & \\
\hline 12.5 & $251 \pm 6$ & $11 \pm 5$ & 95.6 & 6.3 & $1.7 \pm 0.2$ \\
\hline 15 & $258 \pm 12$ & $18 \pm 8$ & 93.0 & 7.5 & $2.7 \pm 0.3$ \\
\hline 20 & $249 \pm 9$ & $26 \pm 11$ & 89.5 & 10.0 & $3.8 \pm 0.1$ \\
\hline
\end{tabular}

높은 것으로 나타났다. 상대적으로 선속도가 증가할수록 $\mathrm{SS}$ 가 여재에 깊이 침투하거나 일부는 유출된다( $\mathrm{Kau}$ and Lawler, 1995).

손실수두는 $12.5,15$ 및 $20 \mathrm{~m} / \mathrm{h}$ 에서 각각 $1.7,2.7$ 및 $3.8 \mathrm{~cm}$ 로 나타나 막힘 현상이 발생하지 않았고, '비점오염 저감시설 설치 및 관리 - 운영 매뉴얼' 상 설치 기준을 만족하는 것으로 나타났다(Table 8). 일반적으로 여과형 비점오염저감시설에서의 강우유출수의 흐름은 직선적이 지 않고 굴절되는 속도벡터의 양상을 보인다. 이 경우 에너지 손실이 발생하며, 수로의 분기각 영향에 의한 단면급축소 효과를 나타내어 수두손실이 더 크게 발생할 수 있다(Song et al., 2014).

Fig. 5는 인과 중금속 제거 효율을 나타내었다. $\mathrm{SS}$ 와 마찬 가지로 인과 중금속의 제거 효율은 선속도가 낮을수록 제거 효율이 높은 것으로 나타났는데, 이는 여과속도가 증가할수 록 유입되는 인공강우유출수 내 물질들이 여재에 접촉하는 시간이 감소하기 때문이다(Park et al., 2015). 인은 선속도 $12.5,15$ 및 $20 \mathrm{~m} / \mathrm{h}$ 조건에서 각각 $98.1,83.6$ 및 $77.6 \%$ 의 제거효율을 나타냈으며, 아연은 각각 $89.8,88.2$ 및 $87.3 \%$ 로, 구리는 각각 $70.1,69.8$ 및 $67.5 \%$ 의 제거 효율을 나타내었다. 단일 물질(single-element)이 함유된 수용액과 달리, 복합 물질(multi-elements)이 포함된 수용액 상에서는 흡착질과 흡착제와의 친화도에 따라 물질 제거 효율과 제거 순서가 결정된다(Xue et al., 2009). 인과 아연 및 구리가 포함된 수용액의 경우 흡착을 위한 슬래그와의 친화도가 아연과 구리가 인에 비해 높아 흡착평형에 먼저 도달하고 선속도에 덜 지배적인 것으로 판단된다. Park et al. (2016)의 연구에서 는 구리가 카드뮴과 아연보다 슬래그에 높은 흡착능을 보였 고, 이러한 경쟁 관계는 흡착제의 흡착 패턴과 선택성에 영향을 주며 수용액 내 성분들의 원자량, 전기음성도와 같은 특성들에 영향을 받는다고 하였다.

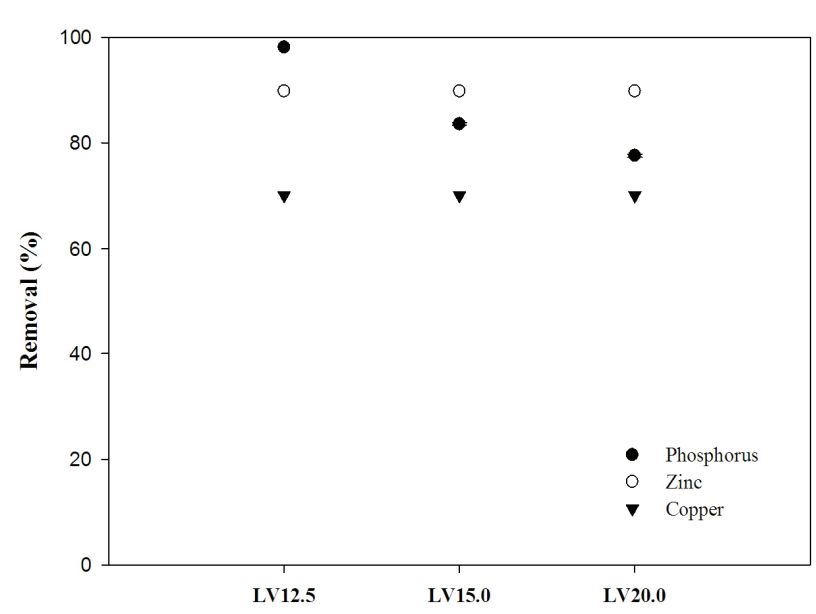

Fig. 5. $\mathrm{P}, \mathrm{Zn}$ and $\mathrm{Cu}$ Removal Efficiency According to the Linear Velocity

\section{4. 결 론}

본 연구에서는 주요 비점오염원인 $\mathrm{SS}$ 뿐 아니라 용존성 인과 중금속도 안정적으로 처리하기 위하여 복합 여재 시스 템을 구성하였으며, 회분식 연구와 pilot column 연구를 통해 처리 효율을 평가하여 다음과 같은 결론을 도출하였으며, 향후 비점오염저감시설에서 이용하기 위한 여재로 충분히 적용할 수 있을 것으로 판단된다.

(1) 소성점토, 제올라이트, 고로슬래그 및 제강슬래그 중 $\mathrm{SS}$ 제거효율은 소성점토가 $91.3 \%$ 로 가장 안정적인 처리 효율을 보였으며, 인과 중금속의 제거 효율은 제강슬래그(인: 94.4 , 아연: $99.9 \%$ )가 가장 안정적인 처리 효율을 나타내었다.

(2) $\mathrm{SS}$ 와 용존성 인, 중금속을 제거하기 위한 복합 여재 시스템으로 pilot column 전단에 소성점토를 적용하고 
후단에 제강슬래그를 적용하는 구성이 효과적임을 확인하였다.

(3) Pilot column test에서 SS, 인, 아연 및 구리는 선속도 $20 \mathrm{~m} / \mathrm{h}$ 조건에서도 각각 $89.5,77.6,87.3,67.5 \%$ 의 안정적인 제거 효율을 나타내었다.

(4) 선속도 $20 \mathrm{~m} / \mathrm{h}$ 에서의 손실수두는 $3.8 \mathrm{~cm}$ 로 나타나 비점오염저감시설 설치 기준을 만족하였다.

(5) 비점오염물질의 안정적인 처리효율 상승을 위해서는 여재의 여과기능 및 흡착량 증대의 필요성이 확인되기 때문에, 탄소나노튜브, 그래핀 등의 탄소나노소재의 적용 가능성에 대한 추가적인 연구를 추진하고자 한다.

\section{감사의 글}

이 논문은 부산대학교 기본연구지원사업(2년)에 의하여 연구되었음.

\section{References}

APHA-AWWA-WEF. (2005). Standard method for the examination of water and wastewater (1st ed.). Washington D.C.: American Public Health Association.

Ayawei, N., Ebelegi, A.N., and Wankasi D. (2017). Modelling and interpretation of adsorption isotherms. J. Chem., Vol. 2017, Article ID 3039817.

Barca, C., Gérente, C., Meyer, D., Chazarenc F., and Andrés, Y. (2012). Phosphorus removal from synthetic and real wastewater using steel slags produced in Europe. Water Res., Vol. 46, No. 7, pp. 2376-2384.

Balkaya, N., and Cesur, H. (2008). Adsorption of cadmium from aqueous solution by phosphogypsum. Chem. Eng. J., Vol. 140, No. 1-3, pp. 247-254.

Bowden, L.I., Jarvis, A.P., Younger, P.L., and Johnson, K.L. (2009). Phosphorus removal from waste water using basic oxygen steel slag. Environ. Sci. Technol., Vol. 43, No. 7, pp. 2476-2481.

Brown, C., Chu, A., van Duin, B., and Valeo, C. (2009). Characteristics of sediment removal in two types of permeable pavement. Water Qual. Res. J. Can., Vol. 44, No. 1, pp. 59-70.

Chen, J., Kong, H., Wu, D., Hu, Z., Wang, Z., and Wang, Y. (2006). Removal of phosphate from aqueous solution by zeolite synthesized from fly ash. J. Colloid Interface Sci., Vol. 300, No. 2, pp. 491-497.

Choi, J., and Shin, C. (2002). Management of nonpoint pollution by reducing storm runoff. KEI-2002-RE-03,
Korea Environment Institute, Seoul.

Drizo, A., Forget, C., Chapuis, R.P., and Comeau, Y. (2006). Phosphorus removal by electric arc furnace steel slag and serpentinite. Water Res., Vol. 40, No. 8, pp 1547-1554.

Erdem, E., Karapinar, N., and Donat, R. (2004). The removal of heavy metal cations by natural zeolites. J. Colloid Interface Sci., Vol. 280, No. 2, pp. 309-314.

Gong, G., Ye, S., Tian, Y., Wang, Q., Ni, J., and Chen, Y. (2009). Preparations of a new sorbent with hydrated lime and blast furnace slag for phosphorus removal from aqueous solution. J. Hazard. Mater., Vol. 166, No. 2-3, pp. 714-719.

Hwang, Y., Seo, Y., Kim, H., Roh, K., Shin, H., and Kim, D. (2017). Optimization of operation and backwashing condition for an upflow stormwater filtration system utilizing ceramic media. J. Korean Soc. Environ. Eng., Vol. 39, No. 8, pp. 478-488.

Jha, V.K., Kameshima, Y., Nakajima A., and Okada, K. (2008). Utilization of steel-making slag for the uptake ammonium and phosphate ions from aqueous solution. J. Hazard. Mater., Vol. 156, No. 1-3, pp. 156-162.

Joshi, U.M., and Balasubramanian, R. (2010). Characteristics and environmental mobility of trace elements in urban runoff. Chemosphere, Vol. 80, No. 3, pp. 310-318.

Kau, S.M., and Lawler, D.F. (1995). Dynamics of deep-bed filtration: Velocity, depth, and media. J. Environ. Eng., Vol. 121, No. 12, pp 850-859.

Kim, E., Rhee, S., Lee, G., Kim, Y., Park, J., and Oh, M. (2011). Assessment of the sorption characteristics of cadmium onto steel-making slag in simulated sea water using batch experiment. J. Korean Geotech. Soc., Vol. 27, No. 4, pp. 43-50.

Kim, S., Kwon, E., Pak, S., Cho, S., Lim, C., and Kang, S. (2010). Identification of operating parameters in auto-discharging filter system for treatment of urban storm water. J. Korean Soc. Water Wastewater, Vol. 24, No. 4, pp. 377-386.

Kim, T., Cho, K., Song, K., Yoon, M., Ahn, K., and Hong, S. (2009). Evaluation of the removal characteristics of pollutant in storm runoff depending on the media properties. J. Korean Soc. Environ. Eng., Vol. 31, No. 7, pp. 483-490.

Kim, Y., Oh, M., Park, J., and Kwon, O. (2014). Removal efficiency of heavy metals and nutrients by zeolite and basic oxygen furnace slag. J. Korea Geo-Environ. Soc., Vol. 15, No. 11, pp. 13-19. 
Ko, J., Lee, S., Heo, C., and Jee, H. (2006). Effect of water quality improvement by porosity of fill materials in mattress/filter system. Journal of the Korean Society of Civil Engineers, Vol. 26, No. 1B, pp. 51-60.

Ministry of Environment (ME). (2014). Standard methods for the measurement of water and wastewater.

Ministry of Environment (ME). (2016) Installation and management of nonpoint pollution control facilities. operation manuals.

Kwon, H., Shin, S., Kim, G., Kim, Y., Shin, D., and Im, T. (2017). The calculation of NPS load per unit area in paddy fields to the Nakdong River Basin. J. Korean Soc. Hazard Mitg., Vol. 17, No. 3, pp. 409-419.

Lee, B., Kim, L., and Goo, B. (2018). Clogging characteristics of stormwater infiltration system according to filter media conditions. J. Korean Soc. Hazard Mitg., Vol. 18, No. 3, pp. 391-398.

Lee, H., and Lee, S. (2009). Runoff characteristics of stormwater in small city urban area. J. Korean Soc. Environ. Eng., Vol. 31, No. 3, pp. 193-202.

Lee, J., Yang, S., and Bang, K. (2015). The performance of pollutant removal using nonpoint treatment filtration device and analysis of the filter backwashing effect. J. Korean Soc. Water Environ., Vol. 31, No. 5, pp. 523-532.

Lim, C., Kim, D., and Ko, S. (2012). Evaluation of downflow granular media filtration for stormwater treatment. J. Korean Soc. Environ. Eng., Vol. 34, No. 10, pp. 684-693.

Okochi, N., and McMartin, D. (2012). A laboratory study of the treatability of synthetic stormwater under varing conditions using electric arc furnace steel slag. Water, Vol. 4, No. 2, pp. 321-344.

Park, K., Cheng, J., and Kim, Y. (2015). Treatment study of the turbid water by high-speed synthetic fiber filter system. J. Korean Soc. Water Environ., Vol. 31, No. 3, pp. 262-271.

Park, J., Kim, H., Kim, S., Lee, S., Kang, B., Kang, S., et al. (2016). Competitive adsorption characteristics of rapid cooling slag in single- and multi-metal solution. Korean J. Environ. Agric., Vol. 35, No. 1, pp. 24-31.

Sakadevan, K., and Bavor, H.J. (1998). Phosphate adsorption characteristics of soils, slags and zeolite to be used as substrates in constructed wetland systems. Water Res., Vol. 32, No. 2, pp 393-399.

Shin, G., Kim, J., Kim, K., and Lee, S. (2011). Phosphorus removal characteristic of the aluminum (III)-loess composite. J. Korean Soc. Environ. Eng., Vol. 33, No. 7, pp. 530-535.

Soller, J., Stephenson, J., Olivieri, K., Downing, J., and Olivieri, A.W. (2005). Evaluation of seasonal scale first flush pollutant loading and implications for urban runoff management. J. Environ. Manage, Vol. 76, No. 4, pp. 309-318.

Song, Y., Lee, H., Park, M., and Park, M. (2014). Analysis of head loss coefficient for non-point pollutants removal equipments with branch angle and crosssection ratio of inflow channel. J. Korean Soc. Hazard Mitg., Vol. 14, No. 4, pp. 379-385.

Xue, Y., Hou, H., and Zhu, S. (2009). Competitive adsorption of copper(II), cadmium(II), lead(II) and zinc(II) onto basic oxygen furnace slag. J. Hazard. Mater., Vol. 162, No. 1, pp. 391-401.

\begin{tabular}{l|l} 
Received & November 15, 2018 \\
Revised & November 19, 2018 \\
Accepted & November 28, 2018
\end{tabular}

